\title{
Oil Palm Mesocarp Fiber as New Lignocellulosic Material for Fabrication of Polymer/Fiber Biocomposites
}

\author{
Yoon Yee Then, ${ }^{1}$ Nor Azowa Ibrahim, ${ }^{1}$ Norhazlin Zainuddin, ${ }^{1}$ \\ Hidayah Ariffin, ${ }^{2}$ and Wan Md Zin Wan Yunus ${ }^{3}$ \\ ${ }^{1}$ Department of Chemistry, Faculty of Science, Universiti Putra Malaysia (UPM), 43400 Serdang, Selangor, Malaysia \\ ${ }^{2}$ Department of Bioprocess Technology, Faculty of Biotechnology and Biomolecular Sciences, Universiti Putra Malaysia (UPM), \\ 43400 Serdang, Selangor, Malaysia \\ ${ }^{3}$ Department of Chemistry, Centre For Defence Foundation Studies, National Defence University of Malaysia, Sungai Besi Camp, \\ 57000 Kuala Lumpur, Federal Territory of Kuala Lumpur, Malaysia
}

Correspondence should be addressed to Nor Azowa Ibrahim; norazowa@science.upm.edu.my

Received 11 July 2013; Accepted 10 November 2013

Academic Editor: Jose Ramon Leiza

Copyright (C) 2013 Yoon Yee Then et al. This is an open access article distributed under the Creative Commons Attribution License, which permits unrestricted use, distribution, and reproduction in any medium, provided the original work is properly cited.

New biocomposites consisting of poly (butylene succinate) (PBS) and various content (0-70 wt\%) of oil palm mesocarp fiber (OPMF) or oil palm empty fruit bunch fiber (OPEFBF) were fabricated by melt blending and subsequently hotpress moulding. The tensile, flexural, and impact properties of those biocomposites were evaluated and compared. Enhancement of flexural modulus of 200 or $150 \%$ was observed with PBS biocomposite loaded with $70 \mathrm{wt} \%$ of OPMF or OPEFBF. PBS/OPMF biocomposites exhibited higher values of tensile, flexural and impact strengths, and tensile and flexural moduli than those of PBS/OPEFBF biocomposites. These results indicated that OPMF feature better reinforcing agent for PBS as compared to that of OPEFBF.

\section{Introduction}

Poly (butylene succinate) (PBS) is a biodegradable polymer synthesized by the polycondensation of 1,4 -butanediol and succinic acid [1]. It has excellent mechanical properties, melt processing capability, and biodegradability [2]. It can be degraded by microorganisms in compost, soil, and seawater $[1,3]$. However, relatively high production cost of PBS as compared to nonbiodegradable polymer has limited many of its applications. Therefore, blending of PBS with low cost natural fiber may produce the required materials at competitive price [3].

Utilization of natural fibers in composite preparation offer several advantages compared to those of synthetic fibers which include low density, low cost, renewability, and biodegradability $[4,5]$. Natural fibers like kenaf $[3,6]$, jute $[2,5]$, coir [7], silk [8], bamboo [9], sisal [10], and oil palm empty fruit bunch [11-13] have been extensively studied for fabrication of polymer/fiber composites. Rozman et al. [11] reported that incorporation of the OPEFBF into polypropylene matrix resulted in an improved tensile modulus but reduced in tensile strength, elongation at break, and impact strength with increasing fiber content.

Biomass of OPMF and OPEFBF are lignocellulosic materials produced in palm oil mill after the oil extraction process. OPEFBF is obtained from the fruit bunch after removal of oil palm fruits whereas OPMF is residue obtained from oil palm fruits after the oil extraction [14]. They are either left in the palm oil mill as wastes or used as boiler fuel to produce steam and to generate power $[13,15]$. The current utilization of these fibers however has created huge environmental pollution to the environment. Due to this reason, this research was carried out to utilize them in a better way as filler for biocomposites preparation. Additionally, the utilization of these fibers in biocomposites preparation will be an added-value of oil palm biomass in the future. Other authors have reported in the past the blending of OPEFBF with high density polyethylene [11], polypropylene [12] and polycaprolactone [13] to fabricate 


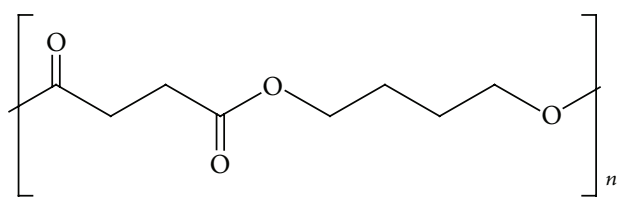

FIGURE 1: Molecular structure of PBS.

TABLE 1: Chemical and mechanical properties of OPMF and OPEFBF [14].

\begin{tabular}{lcc}
\hline & OPMF & OPEFBF \\
\hline Lignin (\%) & 11 & 19 \\
Cellulose (\%) & 60 & 65 \\
Ash content (\%) & 3 & 2 \\
Tensile strength (MPa) & 80 & 248 \\
Young's modulus (MPa) & 500 & 2000 \\
Elongation at break (\%) & 17 & 14 \\
\hline
\end{tabular}

polymer/fiber composites but, so far, there is no literature on reinforcing PBS. In addition, the utilization of OPMF in fabrication of polymer/fiber composite has not been reported previously.

The aim of this paper is to study the potential of OPMF as new lignocellulosic material for fabrication of polymer/fiber biocomposite via mechanical properties comparison between $\mathrm{PBS} / \mathrm{OPMF}$ and PBS/OPEFBF biocomposites. In order to produce price competitive material, the amount of fibers used was increased up to $70 \mathrm{wt} \%$ for fabrication of PBS biocomposites.

\section{Experimental}

2.1. Materials. Poly (butylene succinate) (PBS), under trade name of BIONOLLE 1903MD was purchased from Showa Denko, Japan. It has a density of $1.26 \mathrm{~g} / \mathrm{cm}^{3}$ and melting point of $\sim 115^{\circ} \mathrm{C}$. Its molecular structure is shown in Figure 1. OPEFBF and OPMF were kindly supplied by Sabutek (M) Sdn. Bhd., Malaysia and FELDA Serting Hilir Oil Palm Mill, Malaysia, respectively. The chemical and mechanical properties of OPMF and OPEFBF are given in Table 1.

2.2. Preparation of Fibers. OPMF and OPEFBF were first washed by soaking in distilled water for 24 hour and then rinsed with hot water $\left(60^{\circ} \mathrm{C}\right)$ and acetone prior to drying at $60^{\circ} \mathrm{C}$ in an oven. This process was carried out to remove some impurities from the fibers. The dried fibers were then ground, sieved into size of $150-300 \mu \mathrm{m}$, and stored in a sealed polyethylene bag for biocomposites fabrication.

2.3. Preparation of PBS Biocomposites. PBS, OPMF and $\mathrm{OPEFBF}$ were dried in an oven at $60^{\circ} \mathrm{C}$ prior to processing. PBS biocomposites were prepared by melt blending of PBS with various amount $(0-70 \mathrm{wt} \%)$ of OPMF or OPEFBF in a Brabender internal mixer at $120^{\circ} \mathrm{C}$ with $50 \mathrm{rpm}$ rotor speed. PBS pellet was first introduced into the mixing chamber to melt for $2 \mathrm{~min}$. Subsequently, fibers were added to the mixing
TABLE 2: Formulations of PBS biocomposites.

\begin{tabular}{lccc}
\hline Code & PBS (wt $\%)$ & OPMF (wt\%) & OPEFBF (wt\%) \\
\hline PBS & 100 & 0 & 0 \\
PBS/10 fiber & 90 & 10 & 10 \\
PBS/20 fiber & 80 & 20 & 20 \\
PBS/30 fiber & 70 & 30 & 30 \\
PBS/40 fiber & 60 & 40 & 40 \\
PBS/50 fiber & 50 & 50 & 50 \\
PBS/60 fiber & 40 & 60 & 60 \\
PBS/70 fiber & 30 & 70 & 70 \\
\hline
\end{tabular}

${ }^{*}$ fiber $=$ OPMF or OPEFBF.

chamber and continued mixing for another $13 \mathrm{~min}$. These compounded materials were then compressed into 1 or $3 \mathrm{~mm}$ thick film by hydraulic hotpress also at $120^{\circ} \mathrm{C}$ under pressure of $150 \mathrm{~kg} / \mathrm{cm}^{2}$ for $5 \mathrm{~min}$, followed by cold pressing at $30^{\circ} \mathrm{C}$ for $5 \mathrm{~min}$. The formulations for PBS biocomposites fabrication were given in Table 2 .

2.4. Mechanical Properties. Tensile and flexural tests for PBS and PBS biocomposites were carried out by a Universal Testing Machine (Instron 4302). Load cell of $1 \mathrm{kN}$ was used and the tests were performed at $25^{\circ} \mathrm{C}$. Specimens for tensile and flexural tests were cut according to the standard of ASTM D638-5 and D790, respectively. Crosshead speed of $5 \mathrm{~mm} / \mathrm{min}$ was used for tensile test. Meanwhile, crosshead speed of $1.3 \mathrm{~mm} / \mathrm{min}$ and support span length of $48 \mathrm{~mm}$ were used for flexural test. Their results were expressed in term of tensile or flexural strength, tensile, or flexural modulus and elongation at break. Unnotched Izod impact test for PBS and PBS biocomposites was carried out following the ASTM D256 using an IZOD Impact Tester equipped with a $7.5 \mathrm{~J}$ pendulum at $25^{\circ} \mathrm{C}$. Five specimens were tested for all the tests and the average values were reported. Their standard deviations are expressed in error bar.

2.5. Scanning Electron Microscopy (SEM). The surface morphologies of OPMF, OPEFBF and tensile fracture surfaces of PBS and PBS biocomposites were recorded by a JOEL JSM6400 scanning electron microscope operated at $15 \mathrm{kV}$. The scanning electron micrographs were recorded at the magnification of 200-300x. All the samples were coated with gold by a Bio-rad coating system before viewing to avoid samples' charging.

\section{Results and Discussion}

PBS biocomposites loaded with various amount (0-70 wt\%) of OPMF or OPEFBF were successfully fabricated by melt blending and their tensile, flexural, and impact properties were examined and reported. Initially, PBS biocomposites loaded with $80 \mathrm{wt} \%$ of fibers were also fabricated in our experiment but later excluded from our experiment because the mixing is poor due to insufficient PBS to wet the fiber (fibers and PBS still remained as separated phase after melt blending). Consequently, maximum loading of fibers were 
TABLE 3: Tensile strength, tensile modulus, and elongation at break of PBS, PBS/OPMF, and PBS/OPEFBF biocomposites.

\begin{tabular}{|c|c|c|c|c|c|c|}
\hline \multirow{2}{*}{ Fiber content, (wt\%) } & \multicolumn{2}{|c|}{ Tensile strength, $(\mathrm{MPa})$} & \multicolumn{2}{|c|}{ Tensile modulus, $(\mathrm{MPa})$} & \multicolumn{2}{|c|}{ Elongation at break, (\%) } \\
\hline & OPMF & OPEFBF & OPMF & OPEFBF & OPMF & OPEFBF \\
\hline 0 & \multicolumn{2}{|c|}{$37.31 \pm 0.91^{*}$} & \multicolumn{2}{|c|}{$248.90 \pm 4.40$} & \multicolumn{2}{|c|}{$470.00 \pm 55.20$} \\
\hline 10 & $25.55 \pm 1.60$ & $25.67 \pm 0.39$ & $301.50 \pm 6.41$ & $313.20 \pm 2.40$ & $19.60 \pm 2.87$ & $17.33 \pm 1.29$ \\
\hline 20 & $19.91 \pm 0.95$ & $19.69 \pm 1.01$ & $349.60 \pm 8.36$ & $382.00 \pm 29.60$ & $13.72 \pm 1.37$ & $13.40 \pm 1.38$ \\
\hline 30 & $17.43 \pm 0.69$ & $16.98 \pm 0.88$ & $375.33 \pm 10.89$ & $372.93 \pm 42.86$ & $9.93 \pm 0.90$ & $9.81 \pm 1.73$ \\
\hline 40 & $16.74 \pm 1.19$ & $15.55 \pm 0.34$ & $421.90 \pm 38.60$ & $425.20 \pm 42.80$ & $7.10 \pm 0.57$ & $6.18 \pm 1.96$ \\
\hline 50 & $15.50 \pm 1.04$ & $14.32 \pm 0.46$ & $474.20 \pm 4.24$ & $469.90 \pm 54.20$ & $4.73 \pm 0.22$ & $4.70 \pm 1.00$ \\
\hline 60 & $14.56 \pm 0.66$ & $12.85 \pm 1.28$ & $470.50 \pm 21.70$ & $412.00 \pm 48.80$ & $3.35 \pm 0.06$ & $3.08 \pm 0.42$ \\
\hline 70 & $13.86 \pm 0.73$ & $10.80 \pm 0.83$ & $94.80 \pm 7.60$ & $77.00 \pm 25.46$ & $2.50 \pm 0.29$ & $2.38 \pm 0.10$ \\
\hline
\end{tabular}

${ }^{*}$ Standard deviation.

fixed at $70 \mathrm{wt} \%$. It is interesting to note that the tensile strength of PBS biocomposite loaded with $70 \mathrm{wt} \%$ of OPMF or OPEFBF is 90 or $48 \%$ higher than that of low density polyethylene (7.30 MPa) [5]. This suggests that those biocomposites may have potential application as packaging materials.

\subsection{Mechanical Properties}

3.1.1. Tensile Properties. The tensile strength, tensile modulus, and elongation at break of PBS, PBS/OPMF and PBS/ OPEFBF biocomposites are summarized in Table 3. Neat PBS has a tensile strength of $37.10 \mathrm{MPa}$ and it has decreased after melt blended with OPMF or OPEFBF due to the poor interfacial adhesion between the hydrophobic PBS and hydrophilic fibers [7].

From Table 3, it is noted that the tensile strength of the PBS biocomposites reduces drastically (32-47\%) as fibers loading increase from $0-20 \mathrm{wt} \%$ and beyond that (30$70 \mathrm{wt} \%)$, the reduction is rather small. It is suggested that at low fibers loading, fibers are unable to disperse evenly in the PBS matrix, lead to high stress concentrations, and cause the bond between fiber and matrix to break, hence resulting in a dramatic reduction in tensile strength. Meanwhile, as fibers content increase, fibers may disperse more evenly and oriented, and the stress is more evenly distributed, thus the reduction in tensile strength is rather small.

Although OPEFBF has 3 times higher tensile strength than that of OPMF as shown in Table 1, it is noted that the tensile strengths of PBS/OPMF and PBS/OPEFBF biocomposites are very similar to each other up to $50 \mathrm{wt} \%$ fibers content. As fibers content increase to 60 or $70 \mathrm{wt} \%$, it is interesting to note that the tensile strength of PBS/OPMF biocomposite is 15 or $28 \%$ higher than that of the PBS/OPEFBF biocomposite. This may due to the fact the OPMF is softer and flexible than that of OPEFBF, therefore has higher ability to disperse more evenly and oriented in the PBS matrix, consequently resulted in higher tensile strength. This observation also suggests that OPMF has better reinforcing ability than that of OPEFBF.

Neat PBS shows a tensile modulus of $248.90 \mathrm{MPa}$ and it increases with increasing fibers content up to $50 \mathrm{wt} \%$, and then leveled off. It is noted that PBS/OPMF biocomposites show higher tensile modulus than those of PBS/OPEFBF biocomposites. Enhancement in tensile modulus is probably due to the fibers itself which have higher stiffness or modulus than that of polymer. Meanwhile, the decreased in tensile modulus at high fibers loading (60-70 wt\%) probably due to the decreased in wetability between PBS and fibers resulted from the PBS content not sufficient to wet the surrounding fibers during composite fabrication, leading to poor load transfer between PBS and fibers [7, 16].

PBS is ductile and flexible in nature, so high value of elongation at break (EB) of $470 \%$ is noted. The EB of PBS biocomposites has reduced to around 2.50 or $2.38 \%$ upon addition of $70 \mathrm{wt} \%$ of OPMF or OPEFBF. The decreased in $\mathrm{EB}$ is due to the destroyed structural integrity of PBS by fibers and the rigid structure of fibers [17]. Furthermore, as fiber contents are increased to high extend, the fibers tend to agglomerate and imply poor PBS/fiber adhesion which will then promote the formation of microcracks at the interface, resulting in quicker fracture than that of neat PBS [17]. This result is in good agreement with the result reported by Habibi et al. [18] where the authors claimed that the EB decreased upon fiber addition for composites regardless the nature of the fiber.

3.1.2. Flexural Properties. The flexural strengths and moduli of PBS and PBS biocomposites filled with various content of OPMF or OPEFBF are shown in Figures 2 and 3, respectively. From Figure 2, neat PBS shows a flexural strength of $37.58 \mathrm{MPa}$ and it has decreased to 27.26 and $21.53 \mathrm{MPa}$ or reduction of 27 and $43 \%$ upon addition of $70 \mathrm{wt} \%$ of OPMF or OPEFBF, respectively. The reduction in flexural strength may be ascribed to insufficient wetting of fiber by the polymer matrix with the presence of the fiber bundles and more fiber-fiber interactions as reported by Mohd Ishak et al. [19]. Although the flexural strength of PBS biocomposites decreases with increasing fibers content; however, PBS/OPMF biocomposites still exhibit higher flexural strength than those of PBS/OPEFBF biocomposites at all fiber loading. For instance, the flexural strength of PBS/70 OPMF biocomposite is $27 \%$ higher over PBS/70 OPEFBF biocomposite. This result once again proves that OPMF may have better interfacial adhesion and compatibility with PBS matrix and therefore produce stronger materials.

In contrast to flexural strength, increasing trend is observed in the flexural modulus of PBS biocomposites with increasing fibers content of up to $70 \mathrm{wt} \%$. The PBS/OPMF 


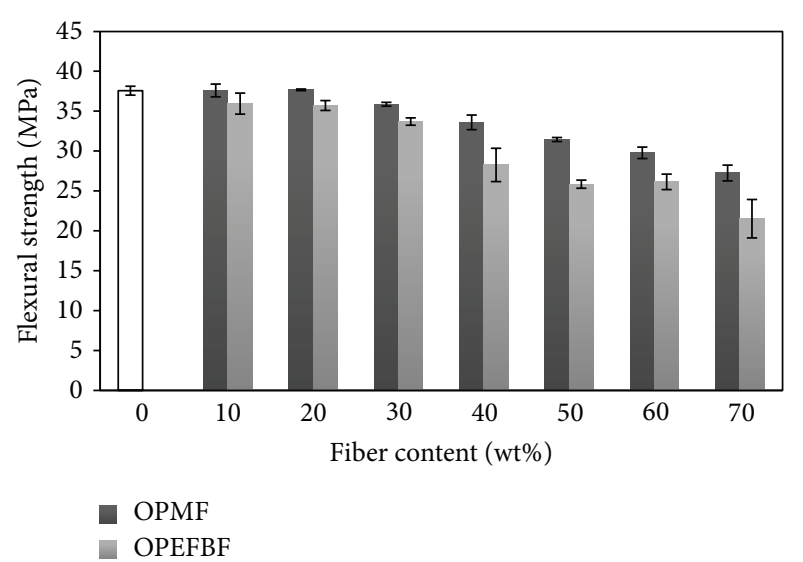

FIgURE 2: Flexural strength of PBS, PBS/OPMF and PBS/OPEFBF biocomposites.

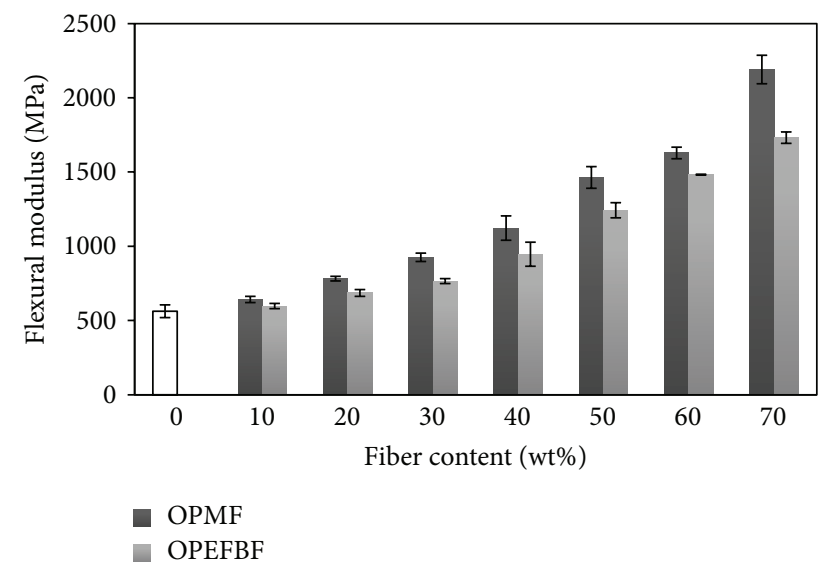

Figure 3: Flexural modulus of PBS, PBS/OPMF, and PBS/OPEFBF biocomposites.

biocomposites show higher flexural moduli than those of PBS/OPEFBF biocomposites at all fiber loading. Improvements of 200 and $150 \%$ are noted for PBS/70 OPMF and $\mathrm{PBS} / 70$ OPEFBF, respectively as compared to that of neat PBS. Lee et al. [6] reported that when natural fibers were incorporated into the polymer matrix, the segmental movement of the polymer chains was hindered; hence, the composites become stiffer and improve their flexural moduli.

3.1.3. Impact Properties. Figure 4 shows the impact strength of un-notched samples of PBS, PBS/OPMF, and PBS/OPEFBF biocomposites. It is evident that the impact strength of $\mathrm{PBS}$ biocomposites is lower than that of neat PBS regardless of type and content of fibers. PBS/OPMF biocomposites show higher degree of impact strength as compared to those of PBS/OPEFBF biocomposites. PBS is ductile or plastic like in nature, can absorb more energy during impact failure, and, hence, has high impact strength. However, the presence of OPMF or OPEFBF in the PBS matrix has turned the ductile behavior of PBS to brittle as indicates by decreasing of impact strength of about $33-84 \%$ or $36-89 \%$, respectively. According to Mat Taib [20], the introduction of stiff fiber in a ductile

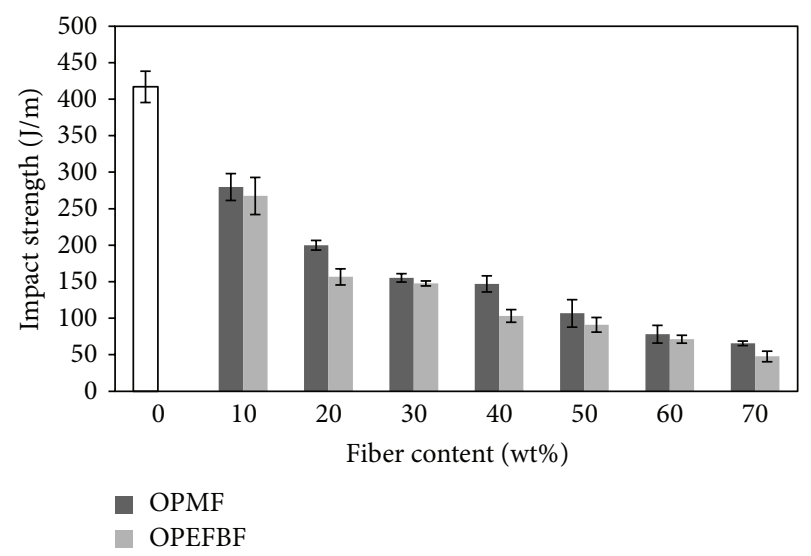

FIGURE 4: Impact strength of PBS, PBS/OPMF, and PBS/OPEFBF biocomposites.

matrix will restrict the segmental motion of the polymer chains, which will consequently limit the deformability of the matrix phase, resulting in low impact strength.

3.2. Morphology. SEM analysis is performed to evaluate the interfacial adhesion between PBS matrix and OPMF or OPEFBF. Figure 5 shows the SEM micrographs of OPMF, OPEFBF, and tensile fractured surfaces of PBS and PBS biocomposites.

PBS exhibits smooth fracture surface. OPMF and OPEFBF also show smooth surfaces but with some impurities covering their surface. Once they are melt blended together, 2 phases (PBS and fibers) are obviously seen as shown in Figures $5(\mathrm{~d})-5(\mathrm{~g})$. The presence of voids on the fractured surfaces of the PBS biocomposites which resulted from fiber pull outs is observed. In addition, gaps are also visible between the PBS and OPMF as shown in Figures 5(d)-5(e). The presence of voids and gaps are evidences of the poor interfacial adhesion resulting from the lack of compatibility between hydrophilic fibers and hydrophobic PBS. Poor interfacial adhesion can then act as a stress concentration point upon exertion of external forces and consequently result in premature failure due to poor stress transfer from matrix to the fibers [21].

At low fibers loading (Figures 5(d)-5(e)), it can be clearly seen that the fibers are not evenly distributed throughout the PBS matrix and the gaps between PBS and fibers are large; however as fibers content increase (Figures $5(\mathrm{f})-5(\mathrm{~g})$ ), fibers become more evenly distributed and oriented in the PBS matrix. This may be the reason why drastic reductions in tensile strength and elongation at break are observed at low fibers loading but rather small at high fiber loading as discussed in Section 3.1.1.

For comparison proposes, the tensile fracture surface micrograph of PBS biocomposite filled with $70 \mathrm{wt} \%$ of OPMF or OPEFBF is presented in Figures 5(g) or 5(h), respectively. The smooth and clean fiber surface shown in Figure 5(h) indicates a weak interaction or poor adhesion between OPEFBF and PBS. Meanwhile, rough fiber surface and few fiber breakages are observed in Figure 5(g), which indicates better 


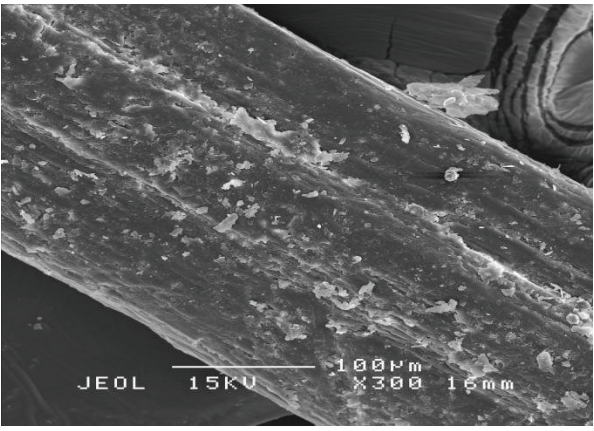

(a)

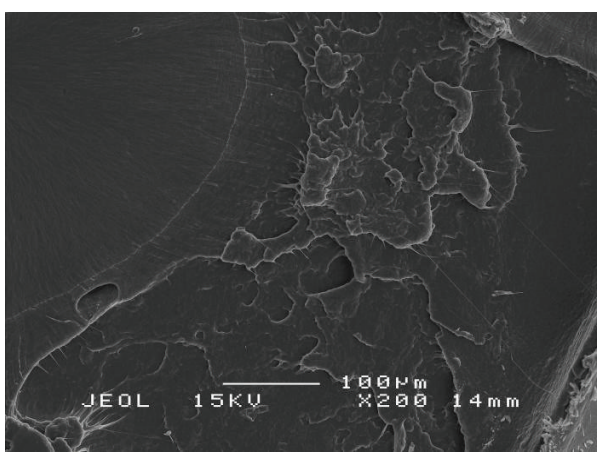

(c)

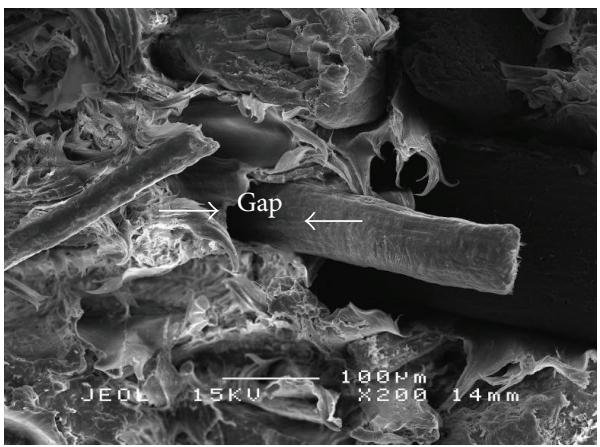

(e)

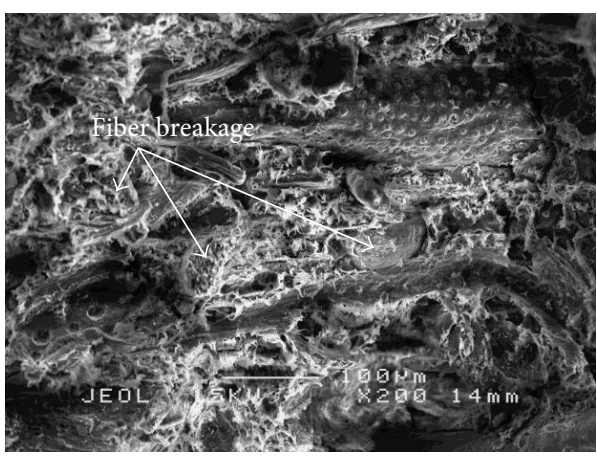

(g)

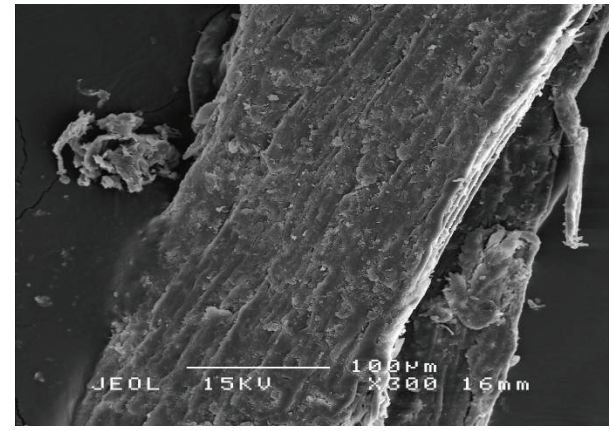

(b)

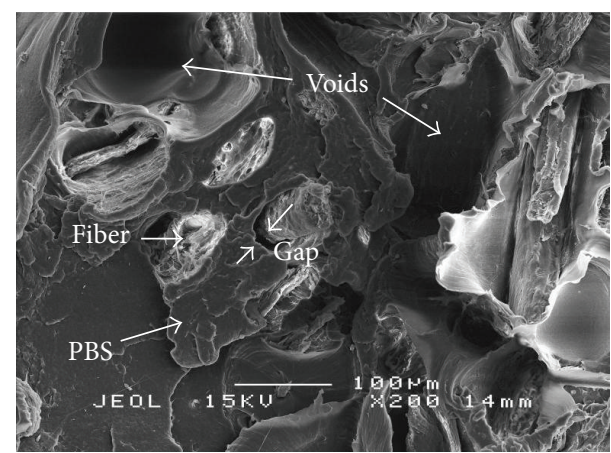

(d)

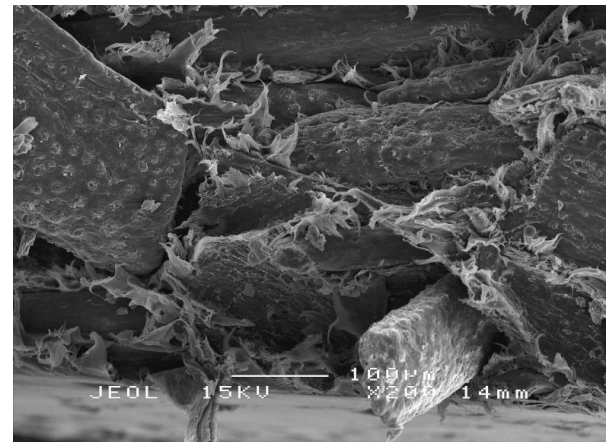

(f)

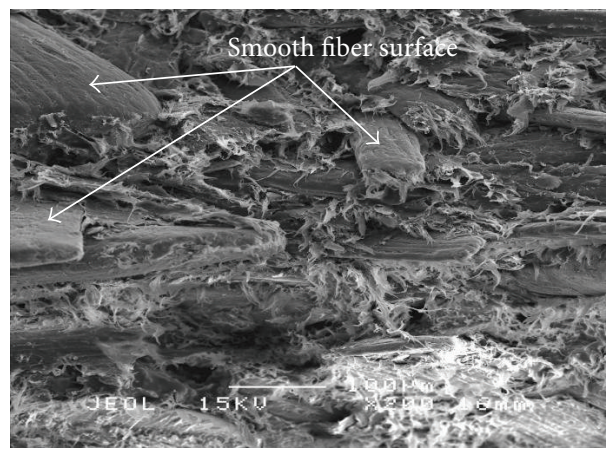

(h)

FIGURE 5: SEM micrographs of (a) OPMF, (b) OPEFBF, (c) PBS, (d) PBS/10 OPMF, (e) PBS/30 OPMF, (f) PBS/50 OPMF, (g) PBS/70 OPMF, and (h) PBS/70 OPEFBF. 
interfacial adhesion between PBS and OPMF. This may be the reason why PBS/OPMF biocomposites especially at high OPMF loading exhibit higher tensile, flexural and impact strengths, and tensile and flexural moduli than those of PBS/ OPEFB biocomposites.

\section{Conclusions}

In this study, PBS biocomposites loaded with high amount of fibers ( $0-70 \mathrm{wt} \%)$ were successfully fabricated by melt blending technique. Flexural and tensile moduli of PBS biocomposites were enhanced by the present of fibers but an opposite trend was observed for elongation at break, tensile, flexural, and impact strengths. Throughout the study, PBS/OPMF biocomposites possessed higher tensile, flexural and impart strengths, and tensile and flexural moduli than those of PBS/OPEFBF biocomposites. It was evident that OPMF could be a potential new lignocellulosic material for fabrication of polymer/fiber biocomposites. Furthermore, the prepared biocomposites may have potential as packaging materials since they have a better tensile strength than that of polyethylene.

\section{Conflict of Interests}

The authors declare that there is no conflict of interests with any financial organization regarding the materials discussed in the paper.

\section{Acknowledgment}

The financial support from Ministry of Education Malaysia through MyPhd is gratefully acknowledged.

\section{References}

[1] H.-S. Kim, H.-J. Kim, J.-W. Lee, and I.-G. Choi, "Biodegradability of bio-flour filled biodegradable poly(butylene succinate) bio-composites in natural and compost soil," Polymer Degradation and Stability, vol. 91, no. 5, pp. 1117-1127, 2006.

[2] L. Liu, J. Yu, L. Cheng, and X. Yang, "Biodegradability of poly(butylene succinate) (PBS) composite reinforced with jute fibre," Polymer Degradation and Stability, vol. 94, no. 1, pp. 9094, 2009.

[3] M. Z. A. Thirmizir, Z. A. M. Ishak, R. M. Taib, S. Rahim, and S. M. Jani, "Kenaf-bast-fiber-filled biodegradable poly(butylene succinate) composites: effects of fiber loading, fiber length, and maleated poly(butylene succinate) on the flexural and impact properties," Journal of Applied Polymer Science, vol. 122, no. 5, pp. 3055-3063, 2011.

[4] A. Jahan, M. M. Rahman, H. Kabir et al., "Comparative study of physical and elastic properties of jute and glass fiber reinforced LDPE composites," International Journal of Scientific and Technology Research, vol. 1, pp. 68-72, 2012.

[5] V. Tserki, P. Matzinos, and C. Panayiotou, "Novel biodegradable composites based on treated lignocellulosic waste flour as filler. Part II. Development of biodegradable composites using treated and compatibilized waste flour," Composites A, vol. 37, no. 9, pp. 1231-1238, 2006.
[6] J. M. Lee, Z. A. Mohd Ishak, R. Mat Taib, T. T. Law, and M. Z. Ahmad Thirmizir, "Mechanical, thermal and water absorption properties of kenaf-fiber-based polypropylene and poly(butylene succinate) composites," Journal of Polymers and Environment, vol. 21, pp. 293-302, 2013.

[7] T. H. Nam, S. Ogihara, N. H. Tung, and S. Kobayashi, "Mechanical and thermal properties of short coir fibre reinforced poly(butylene succinate) biodegradable composites," Journal of Solid Mechanics and Materials Engineering, vol. 5, pp. 251-262, 2011.

[8] S. M. Lee, D. Cho, W. H. Park, S. G. Lee, S. O. Han, and L. T. Drzal, "Novel silk/poly(butylene succinate) biocomposites: the effect of short fibre content on their mechanical and thermal properties," Composites Science and Technology, vol. 65, no. 3-4, pp. 647-657, 2005.

[9] L. Bao, Y. W. Chen, W. H. Zhou, Y. Wu, and Y. L. Huang, "Bamboo fibers@ @oly(ethylene glycol)-reinforced poly(butylene succinate) biocomposites," Journal of Applied Polymer Science, vol. 122, no. 4, pp. 2456-2466, 2011.

[10] Y. H. Feng, Y. J. Li, B. P. Xu, D. W. Zhang, J. P. Qu, and H. Z. He, "Effect of fiber morphology on rheological properties of plant fiber reinforced poly(butylene succinate) composites," Composites B, vol. 44, pp. 193-199, 2013.

[11] H. D. Rozman, H. Ismail, R. M. Jaffri, A. Aminullah, and Z. A. M. Ishak, "Mechanical properties of polyethylene-oil palm empty fruit bunch composites," Polymer-Plastics Technology and Engineering, vol. 37, no. 4, pp. 495-507, 1998.

[12] N. A. Ibrahim, N. Hashim, M. Z. Abdul Rahman, and W. M. Z. Wan Yunus, "Mechanical properties and morphology of oil palm empty fruit bunch-polypropylene composites: effect of adding ENGAGE 7467," Journal of Thermoplastic Composite Materials, vol. 24, no. 5, pp. 713-732, 2011.

[13] M. Z. Abdul Hamid, N. A. Ibrahim, W. Md Zin Wan Yunus, K. Zaman, and M. Dahlan, "Effect of grafting on properties of oil palm empty fruit bunch fiber reinforced polycaprolactone biocomposites," Journal of Reinforced Plastics and Composites, vol. 29, no. 18, pp. 2723-2731, 2010.

[14] M. S. Sreekala, M. G. Kumaran, and S. Thomas, "Oil palm fibers: morphology, chemical composition, surface modification, and mechanical properties," Journal of Applied Polymer Science, vol. 66, no. 5, pp. 821-835, 1997.

[15] H. Lik Nang Lau, Y. M. Choo, A. N. Ma, and C. H. Chuah, "Selective extraction of palm carotene and vitamin E from fresh palm-pressed mesocarp fiber (Elaeis guineensis) using supercritical $\mathrm{CO}_{2}$," Journal of Food Engineering, vol. 84, no. 2, pp. 289-296, 2008.

[16] M. W. Lee, S. O. Han, and Y. B. Seo, "Red algae fibre/poly(butylene succinate) biocomposites: the effect of fibre content on their mechanical and thermal properties," Composites Science and Technology, vol. 68, no. 6, pp. 1266-1272, 2008.

[17] L. F. Liu, J. Y. Yu, L. D. Cheng, and W. W. Qu, "Mechanical properties of poly(butylene succinate) (PBS) biocomposites reinforced with surface modified jute fibre," Composites $A$, vol. 40, no. 5, pp. 669-674, 2009.

[18] Y. Habibi, W. K. El-Zawawy, M. M. Ibrahim, and A. Dufresne, "Processing and characterization of reinforced polyethylene composites made with lignocellulosic fibers from Egyptian agro-industrial residues," Composites Science and Technology, vol. 68, no. 7-8, pp. 1877-1885, 2008.

[19] Z. A. Mohd Ishak, B. N. Yow, B. L. Ng, H. P. S. Khalil, and H. D. Rozman, "Hygrothermal aging and tensile behavior of injection-molded rice husk-filled polypropylene composites," 
Journal of Applied Polymer Science, vol. 81, no. 3, pp. 742-753, 2001.

[20] R. Mat Taib, Effect of fiber surface treatment and water absorption on the mechanical properties of steam-exploded Acacia mangium fiber filled polypropylene composites [Ph.D. dissertation], Universiti Sains Malaysia, 2003.

[21] H.-S. Yang, H.-J. Kim, H.-J. Park, B.-J. Lee, and T.-S. Hwang, "Water absorption behavior and mechanical properties of lignocellulosic filler-polyolefin bio-composites," Composite Structures, vol. 72, no. 4, pp. 429-437, 2006. 

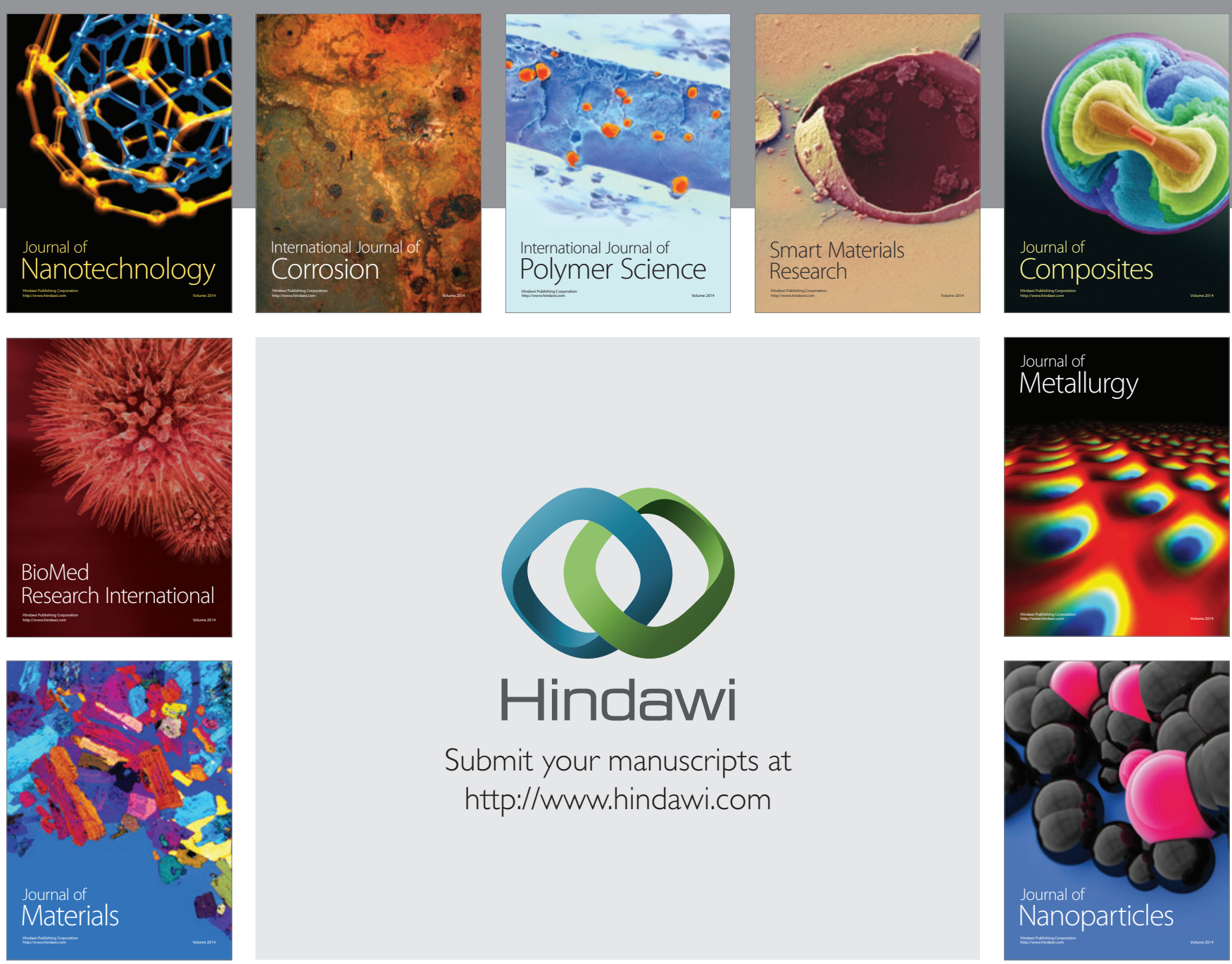

Submit your manuscripts at http://www.hindawi.com
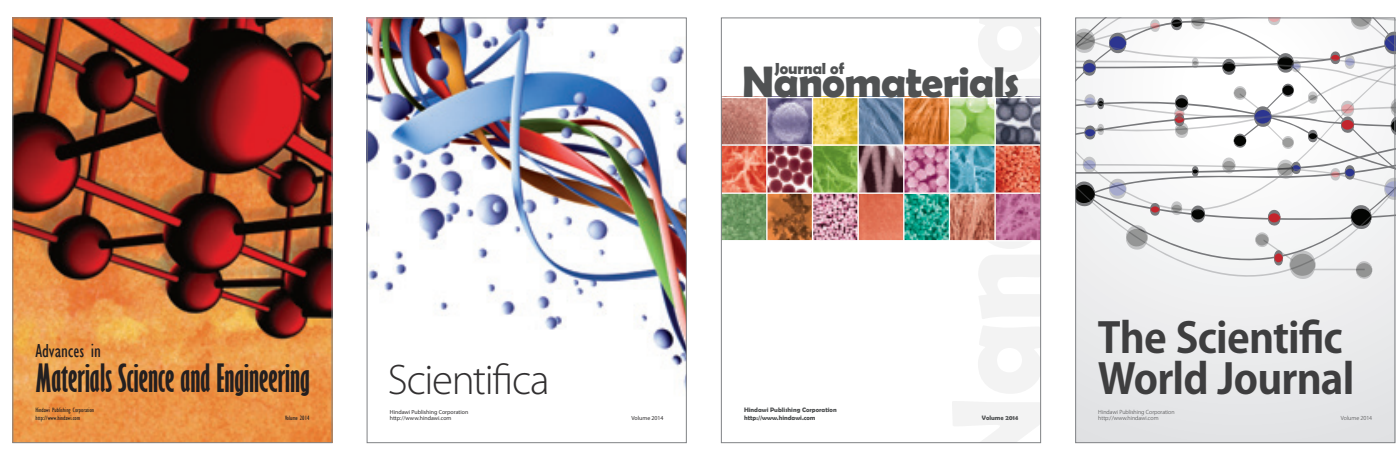

\section{The Scientific World Journal}
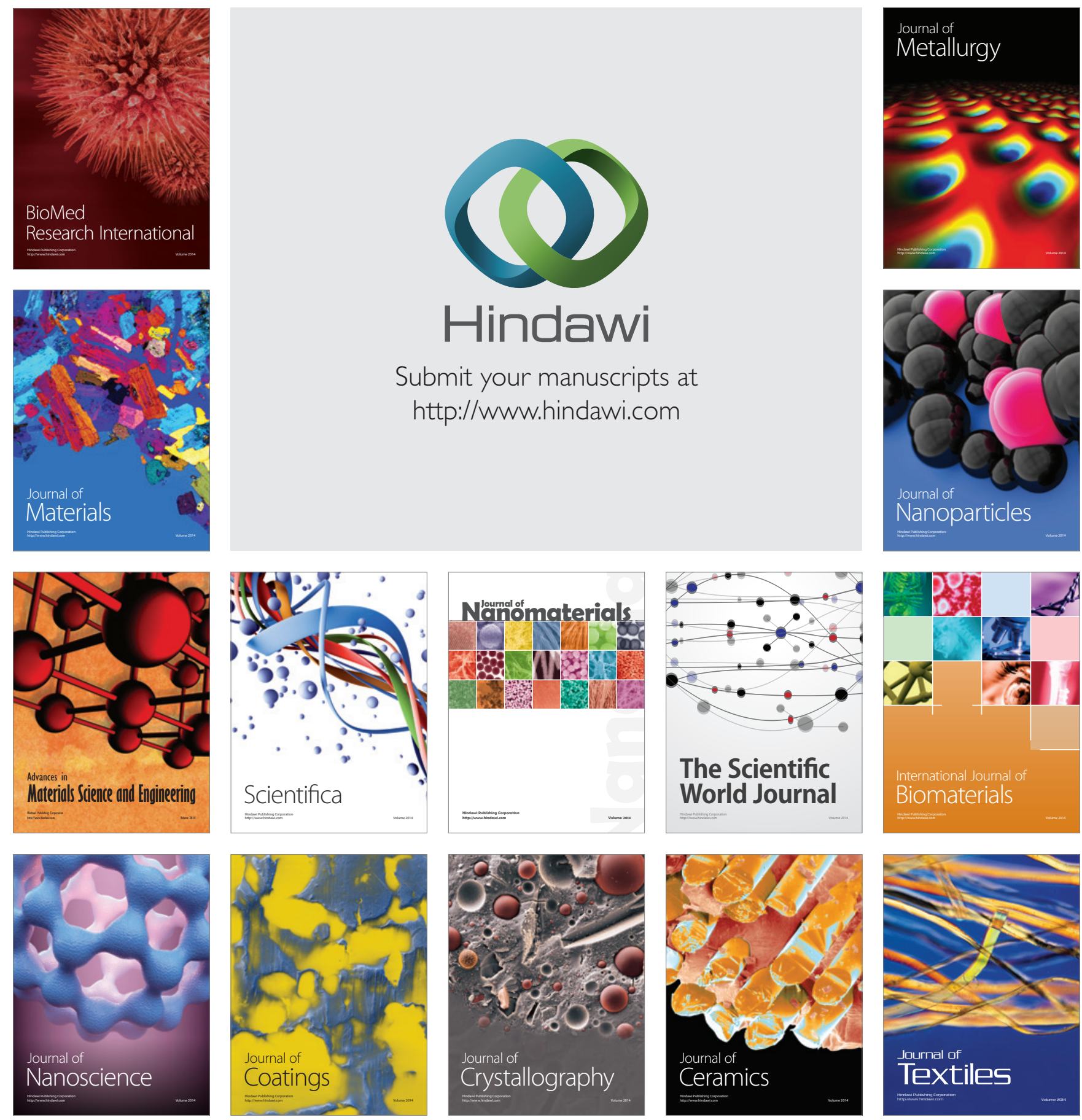